\title{
Design and Implementation of Fuzzy Rule Based Expert System for Employees Performance Appraisal in IT Organizations
}

\author{
Ashima Aggarwal \\ Department of Computer Science \&Engineering, Lovely Professional University, Phagwara, Punjab (India)-144411 \\ Email:ashimasagitarius@gmail.com, \\ Gour Sundar Mitra Thakur \\ Department of Computer Science \&Engineering, Dr. B. C. Roy Engineering College, Durgapur, West Bengal (India)- \\ 713206 \\ Email: cse.gsmt@gmail.com
}

\begin{abstract}
Performance Appraisal of employees plays a very critical role towards the growth of any organization. It has always been a tough task for any industry or organization as there is no unanimous scientific modus operandi for that. Performance Appraisal system is used to assess the capabilities and productiveness of the employees. In assessing employee performance, performance appraisal commonly includes assigning numerical values or linguistic labels to employees performance. However, the employee performance appraisal may include judgments which are based on imprecise data particularly when one employee tries to interpret another employee's performance. Thus, the values assigned by the appraiser are only approximations and there is inherent vagueness in the evaluation. By fuzzy logic perspective, the performance of the appraisee includes the evaluation of his/her work ability, skills and adaptability which are absolutely fuzzy concepts that needs to be define in fuzzy terms. Hence, fuzzy approach can be used to examine these imprecise and uncertainty information. Consequently, the performance appraisal of employees can be accomplished by fuzzy logic approach and different defuzzification techniques are applied to rank the employees according to their performance, which shows inconsequential deviation in the rankings and hence proves the robustness of the system.
\end{abstract}

Index Terms - Fuzzy Expert System, Fuzzy Rule, Employee Performance Appraisal

\section{INTRODUCTION}

Information Technology(IT) organizations are regarded to be one of the "hot sectors" for investment in India. Indian software services are increasing at a extraordinary pace in terms of both profit and global development of customers. IT Organizations requires the proficient employees. It has been noticed that when employees wish to leave an organization, it is plausible that they engage in deviant behaviors or reduce their efforts for performance. Employee deviance and low performance orientation and citizenship behaviors can not only lead to poor individual performances but also bad for the organization's overall-well being. With the business of IT Organizations heavily dependent on on- site clients, these behaviors can, in turn, leads to poor customer relationships [1]. In large organizations, performance appraisal of employees has always been a hectic and complex exercise for the Management and Department of Human and Resources (HRD). On the other hand performance appraisal plays an important and critical role in managing employees effectively, especially in the light of recent economic ups and downs globally, which has compelled both private and public organizations to improve their performances and save resources wherever possible [2].

The main goal of performance appraisal is to access, summarize the performance of the employees, and develop a plan to enhance and improve overall performance towards the successful growth of the organizations. Based on kinds and extent of different organizations various approaches of performance appraisal are adopted by the management to evaluate the performance of their employees. From employees' point of view the purposes of performance appraisal are [3]

a) Tell me what you want me to do,

b) Help me improve my performance and

c) Reward me for doing well.

Therefore, the first and most important task in the performance appraisal is assessing the performance of the employees. As, usually, employees are involved in various kinds of activities that directly or indirectly influence the overall performance of an organization, evaluation of performance has never been an easy task. There are two types of measures used in performance appraisal: Objective measures and Subjective measures. Objective measures can easily be drawn into a number like number of projects completed by the employee but here we are considering the Subjective measures that are not directly quantifiable like motivation, leadership, etc.

A lot of research on Performance Appraisal System has been discussed for years [16-20]; however, many organizations still languish from the uncertainty of measuring the performance of employees. The intention of this analysis is to measure the performance appraisal 
of employees by fuzzy set theory which will generate the accurate data and with the increase in speed.

The proposed model is supposed to work in two stages: firstly, identifying the critical factors, where all the critical factor directly or indirectly influence the performance of employees and secondly, developing a fuzzy expert system to manipulate those critical factors of employees with the help of fuzzy rule base and hence evaluating the performance of employees. The influential certainty of each feature evaluated from experts is also reviwed.

Another study [4] provides different types of Technical Skills such as Foundation Skills, Operational Skills, Essential Skills and Non Technical Skills such as Project Management Skills, Problem/Opportunity Skills, Relationship Skills that are required to evaluate the performance of empoyees. Moon Chiung (2007) suggested the main factors such as service rating, multiarea aptitude, growth potential and innovativeness for measuring the performance [5].

When the research was conducted on Chinese Engineering Managers, three factors were considered:

i) Behavioral Performance: Indicates manager's enthusiasm and endeavour in the job.

ii) Personal Motivation: Indicates manager's motivating approaches and methods. And

iii) Oranizing task: Organizing task and human assets.

Engineering Managers show a binary role as an Engineer and Manager in their departments. There are two types of behaviors related with the job.

i) Direct behavior, labelled as task performance which includes technical management performance and leadership performance.

ii) Indirect behavior, named as contextual performance includes personal relationship faciliation and job dedication.

The factor analysis technique is used to calculate the performance which shows that Chinese Managers perform better in oranizing task than Behavioral Performance and Personal Motivation [6]. In this paper, in section 2,the basic idea fuzzy expert system has been discussed and the general architecture for performance appraisal using fuzzy inference system has been introduced. In section 3 , the full design and implementation of the proposed fuzzy expert system on 10 employees from the IT Organization using MATLAB(R2010a) and finally the results are analysed.

\section{FUZZY EXPERT SYSTEM}

There are many real world problems like intelligent control systems, process diagnostion, fault detection, medical diagnosis, site evaluation,strategic planning, for which solutions are something more than simple reasoning; requiring some expertise to solve. So the use of expert system, a computer system capable of representing and reasoning about some knowledge rich domain with a view to solving problems and giving advice [7] became very popular.
The main difference of Expert System over any other conventional software applications is its effective reasoning capability as they process knowledge instead of data or information [8]. Expert System are very advantageous where the problem area is vast and complex and almost impossible to solve with the help of conventional approaches.

Lotfi A. Zadeh (1965) introduced the concept of fuzzy set theory [9]. Fuzzy logic act as an wonderful idea to near the interspace between human reasoning and computational logic.Fuzzy logic can be used to handle vague, ambiguous or imprecise information. A fuzzy expert system consist of fuzzy membership functions and rules.

In case of crisp environments, a classical set $\mathrm{A}, \mathrm{A}$ in $\mathrm{X}$ is defined as a collection of elements or objects $\mathrm{x} \in \mathrm{X}$, where $\mathrm{X}$ be space of objects and $\mathrm{x}$ is a generical element such that $\mathrm{x}$ can either belong or not belong to the set $\mathrm{A}$. A fuzzy set $A$ in $X$ is defined as a set of ordered pairs $A=\{(x, \mu A(x)) \mid x \in X\}$ where $\mu A(x)$ is the membership function for fuzzy set. Here $x$ can have any value between 0 and 1 such that $\mathrm{x}$ has belongingness and nonbelongingness upto some extent [10]. Thus, unlike crisp sets, in fuzzy set membership is a continuous concept.Generally fuzzy sets are very useful in representing linguistic variables. For example, Speed can be considered a fuzzy linguistic variable whose members can be Slow, Fast,Very fast etc. Fuzzy expert system is such an expert system which uses fuzzy logic instead of Boolean logics in its knowledge base and drives conclusion from user inputs and fuzzy inference process.

Fuzzy Logic rules are generally expressed in the form of IF...THEN and AS...AND...THEN. For example,

"If it is very humid today and also very hot,THEN there is a higher chance of rain".

Or,

"As it is very humid today AND also very hot,THEN there is a higher chance of rain".

Clearly, this type of representation is more valid in real life applications, which is a strength of fuzzy expert system. Fuzzy Expert System is used for decision making like assigning jobs to individuals [11], technology transfer from large organizations to small organizations [12] and for inventory classification [13].

\section{A. Architecture of Fuzzy Expert System}

A typical fuzzy expert system has following three modules [14]:

Fuzzy Knowledge Base: Knowledge Base is made up of rule base and database where rule base consist of fuzzy If-then rules and the database defines the membership functions of the fuzzy sets used in the fuzzy rules [13]. A knowledge base combines the knowledge of multiple human experts.Knowledge Base stores all relevant information, data,rules, cases and relationships used by the expert system.

The rules are of following form

If $\mathrm{X}$ is high $\mathrm{AND} \mathrm{Y}$ is low then $\mathrm{Z}$ is medium.

Where $\mathrm{X}$ and $\mathrm{Y}$ are fuzzy linguistic input variables and high,low are possible linguistic values of $\mathrm{X}$ and $\mathrm{Y}$ 
respectively.Similarly $\mathrm{Z}$ is a fuzzy linguistic output variable and medium is its linguistic value. The antecedent describes to what degree the rule applies where the rule consequent assigns a membership function to each one or more output variables [10].

Interference Engine: The interference engine seek information and relationship from the knowledge base and to provide answers, predictions, and suggestions in the way a human expert would.The interference engine must find the right facts, interpretations and rules and assemble them correctly. Two types of interference mechanisms are commonl used. Backward chaining is the process of starting with the conclusions and working backward to the supporting facts. Forward chaining starting with the facts and work forward to the conclusions [10]. Deffuzification of results is also done in this module.

User Interface: This module provides all the interactions of the users with the system. This module is used to accept inputs from the users, display the results or outcomes of the inference process.Explanation facility is the major characteristic of any Expert System.This module interprets and explains the reasoning outcomes.

In this paper Fuzzy Toolbox of MATLAB interface is used for this purpose. The broad architecture of the proposed fuzzy inference system for the performance appraisal of employees is depicted in the following Fig. 1.

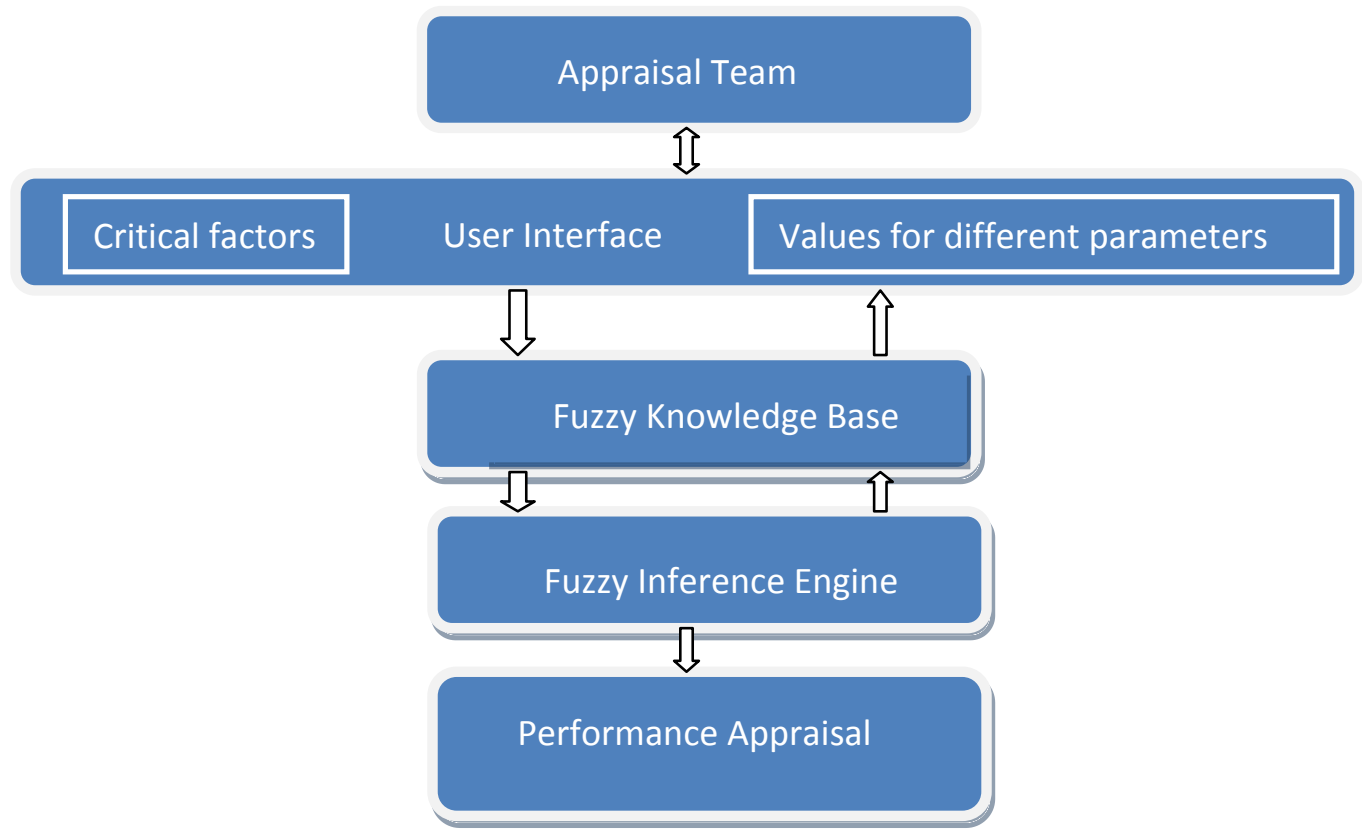

Fig. 1. Architecture of Fuzzy Inference System for Employee Performance Appraisal

Every organization has a seperate Appraisal Team from HR department to evaluate the performance of employees in their organization. The team first identifies those critical factors, which directly or indirectly influenced employees' performance for the given period for which the appraisal is being carried out.After deciding those factors,they set up values for those parameters for all the employees being appraised.Providing values to some of these parameters sometimes may be a tedious task, in that case team might have to conduct some test or interview or they have to mark directly based on the superior remarks.After that all the details are stored in fact base by using some user interface.Then the parameters are fuzzify and fuzzy knowledge base is created,which is basically a collection of fuzzy rules. This fuzzy rule construction is the most important task in this model as the overall performance of the system depends highly on the robustness of this rulebase.To develop this rule base it is always advised to hire a knowledge engineer who elicits knowledge from the domain experts and transfer those elicited knowledge into rule base.Then those fuzzy rules are process on the facts in the working memory in the fuzzy interference engine by applying fuzzification method.At the end of the outcome of the fuzzy interference engine are defuzzified to rank the employees based on their performance.

\section{DESIGN OF THE FUZZY EXPERT SYSTEM}

General design of the proposed fuzzy expert system for employee performance involves the following steps depicted in Fig. 2.

As mentioned earlier,design and implementation of the proposed model has been discussed below according to the design procedure depicted in figure for employees of IT Organization.

\section{A. Identification of Critical Factors}

This is the initial and one of the most important stages in developing any Fuzzy Expert System.It is found that there are many factors that directly or indirectly 
contribute in evaluating the performance of employees. Table 1 shows the descriptions of Performance Appraisal influential factors and sub-factors in the study. Some of the factors are taken from the University of Arizona, Pinellas County and many other Organizations:-

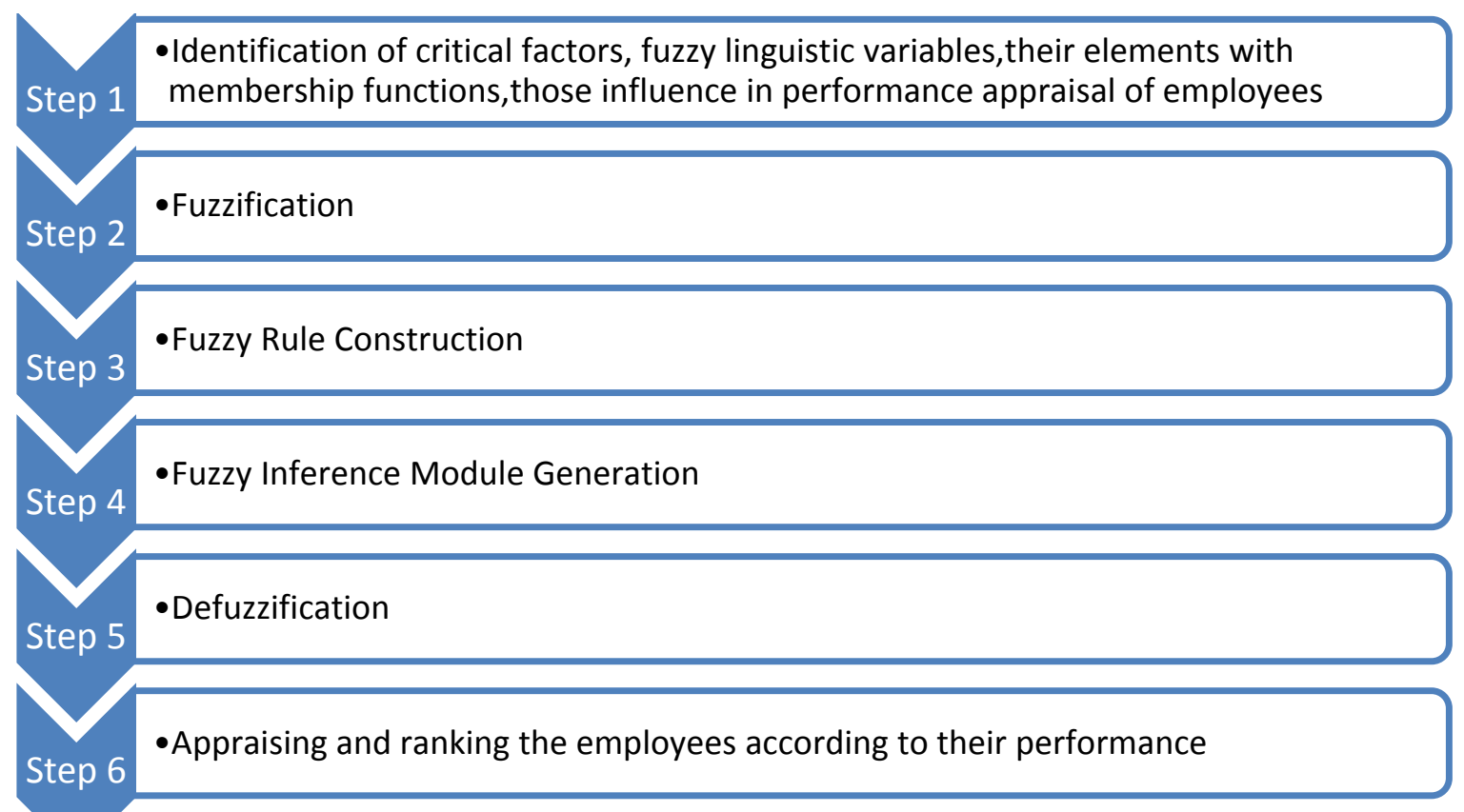

Fig. 2. Fuzzy Inference Process for Employee Performance Appraisal

Table 1. Description of Influential Factors and Sub-Factors

\begin{tabular}{|c|c|c|}
\hline Factors & Sub-Factors & Description \\
\hline \multirow{4}{*}{$\begin{array}{c}\text { General } \\
\text { Performance }\end{array}$} & $\begin{array}{l}\text { Individual } \\
\text { Quality }\end{array}$ & $\begin{array}{l}\text { It contains qualities of an individual such as adaptability, motivation, innovation, initiative, } \\
\text { responsibility, } \\
\text { Work habits, analytical skills. }\end{array}$ \\
\hline & Soft Skills & It includes communication skills, stress tolerance. \\
\hline & Job Related Skills & It includes customer focus, customer service and job knowledge. \\
\hline & Management Skills & $\begin{array}{l}\text { Extent to which employee demonstrates effective management abilities and overall results. It } \\
\text { includes judgment, planning and organizing, problem solving and decision making, } \\
\text { productivity, quality of work, quantity of work, resourcefulness and time management. }\end{array}$ \\
\hline \multirow{4}{*}{ Supervisory } & Cost Effectiveness & $\begin{array}{l}\text { The extent to which employee seeks best use of materials, equipment, and staff to maximize } \\
\text { efficiency and effectiveness. }\end{array}$ \\
\hline & $\begin{array}{l}\text { Delegation and } \\
\text { Supervisory Skills }\end{array}$ & $\begin{array}{l}\text { The extent to which the employee shows the ability to effectively authorize work and } \\
\text { supervise subordinates. }\end{array}$ \\
\hline & Staff Relations & The extent to which the employees effectively oversee and facilitate staff. \\
\hline & $\begin{array}{l}\text { Supervisory } \\
\text { Feedback }\end{array}$ & $\begin{array}{l}\text { Degree to which employee prepares thorough and objective annual appraisals i.e. provides } \\
\text { informal performance feedback on a regular basis. }\end{array}$ \\
\hline \multirow{3}{*}{$\begin{array}{l}\text { Team } \\
\text { Based }\end{array}$} & Consensus Building & $\begin{array}{l}\text { The extent to which the employee builds and maintains work relationships and contacts needed } \\
\text { to effectively address problems and opportunities associated with their position. }\end{array}$ \\
\hline & Teamwork & The degree to which the employee works well in a team setting. \\
\hline & $\begin{array}{l}\text { Working with } \\
\text { others/Cooperation }\end{array}$ & Extent to which employee works effectively with customers, co-workers and the public. \\
\hline
\end{tabular}

In Fig 3, all the critical factors considered are depicted as a heirarchy and Table 2 gives sample record of 10 employees from Adobe Systems, Noida in the range of 0 to 10 for those factors : 


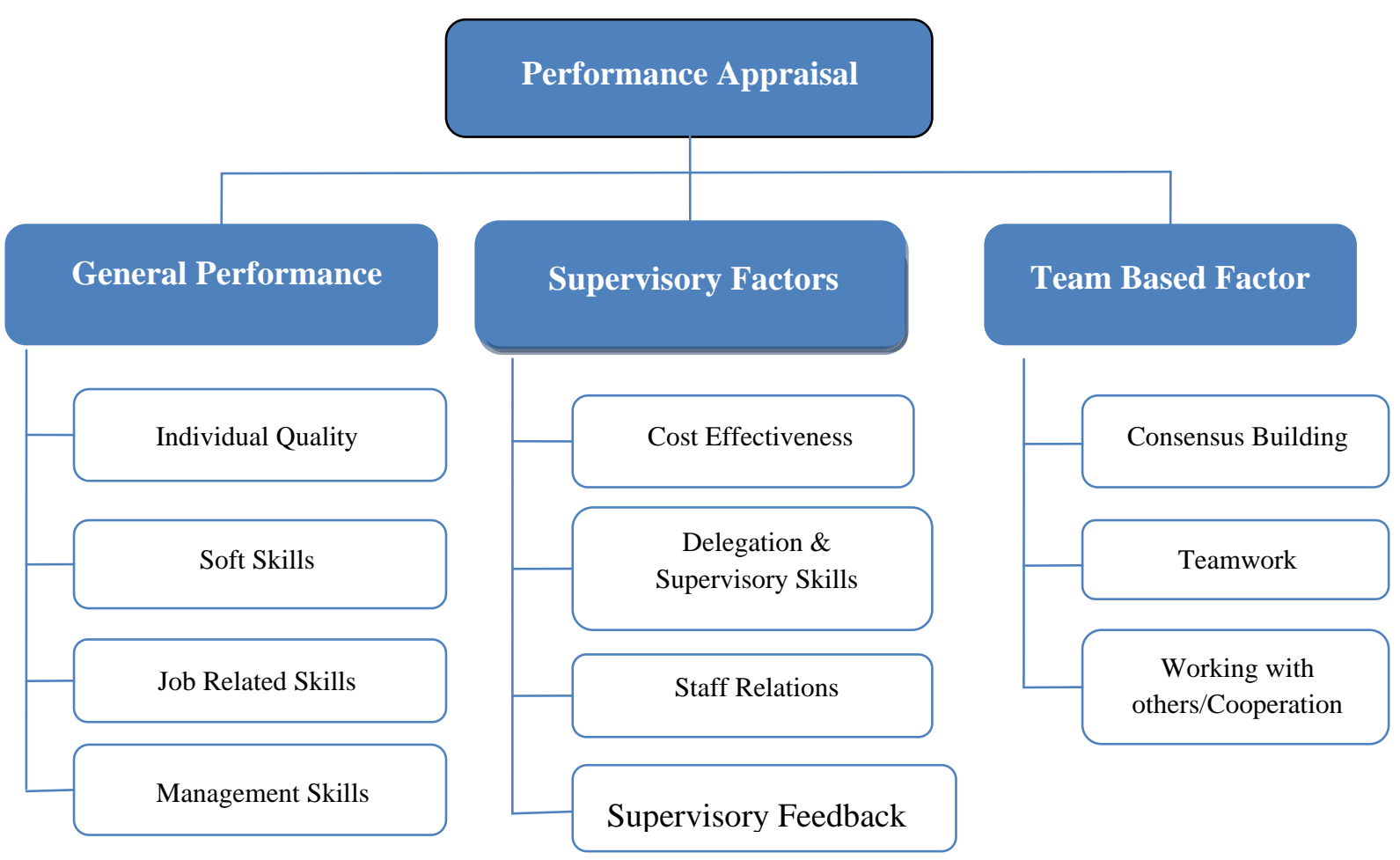

Fig. 3. Hierarchal Structure of Performance Appraisal System

Table 2. Sample records of employees in IT Organization.

\begin{tabular}{|c|c|c|c|c|c|c|c|c|c|c|c|}
\hline ذِ & 焉 & 竞 & 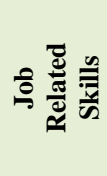 & 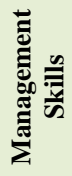 & نे & 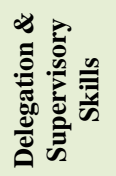 & 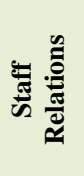 & 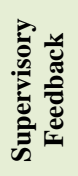 & 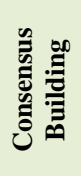 & 泀 & 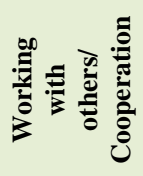 \\
\hline E1 & 4.6 & 5.4 & 6.8 & 3.4 & 2.7 & 5.8 & 6.7 & 7.4 & 2.43 & 2.71 & 2.69 \\
\hline E2 & 8.9 & 9.8 & 8.7 & 6.8 & 8.3 & 8.7 & 7.6 & 9.3 & 8.7 & 8.1 & 8.4 \\
\hline E3 & 2.3 & 4.5 & 5.6 & 6.7 & 7.6 & 5.8 & 2.2 & 8.7 & 6.9 & 3.3 & 7.6 \\
\hline E4 & 6.2 & 8.6 & 7.5 & 3.1 & 3.2 & 5.7 & 5.1 & 6.9 & 6.9 & 3.3 & 7.6 \\
\hline E5 & 7.8 & 4.3 & 3.3 & 7.8 & 2.1 & 7.9 & 2.4 & 4.5 & 4.1 & 3.2 & 6.5 \\
\hline E6 & 7.8 & 3.2 & 2.9 & 3.2 & 2.3 & 4.1 & 7.6 & 8.3 & 3.2 & 5.6 & 7.9 \\
\hline E7 & 2.3 & 4.5 & 5.6 & 6.7 & 8.3 & 8.7 & 7.6 & 9.3 & 7.1 & 5.6 & 4.2 \\
\hline E8 & 7.8 & 4.2 & 2.1 & 7.7 & 5.7 & 4.6 & 7.8 & 6.4 & 5.4 & 6.7 & 8.7 \\
\hline E9 & 4.6 & 5.4 & 6.8 & 3.4 & 2.7 & 2.3 & 7.3 & 7.5 & 7.3 & 7.7 & 8.2 \\
\hline E10 & 6.7 & 4.3 & 5.3 & 5.8 & 7.6 & 7.8 & 8.4 & 8.3 & 8.7 & 8.1 & 8.4 \\
\hline
\end{tabular}

\section{B. Fuzzification}

Fuzzification is the process of converting crisp inputs to fuzzy values. When uncertainty arises due to ambiguity or vagueness in dealing with a variable, then that variable is considered fuzzy and can be represented by a membership function. When the inputs generated from a piece of hardware or drive from sensor measurement then these crisp numerical values could be fuzzified in order for them to be used in a fuzzy inference system [15]. In this phase, the critical factors identified for performance evaluation are considered as inputs for the fuzzy inference system and are represented in the form of fuzzy linguistic variables with their member elements. Then each variable is assigned with fuzzy membership using triangular membership functions. Table 3 is prepared after discussion with various experts in different IT organizations. 
Design and Implementation of Fuzzy Rule

Based Expert System for Employees Performance Appraisal in IT Organizations

Table 3. Different fuzzy linguistic variables and their fuzzy elements

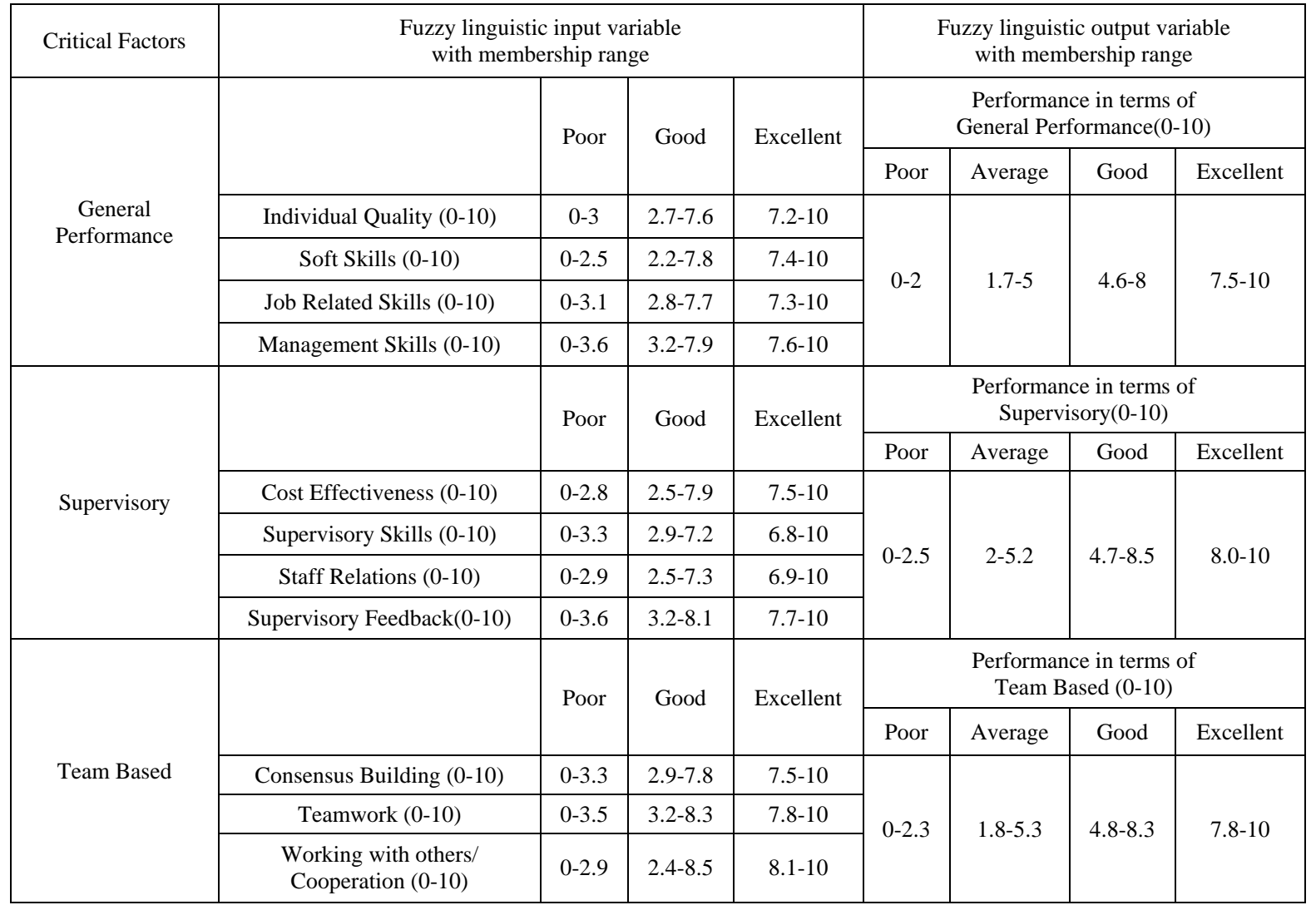

Fig. 4 shows a sample fuzzification step in using Fuzzy Toolbox in MATLAB for the General Performance factor as mentioned above.

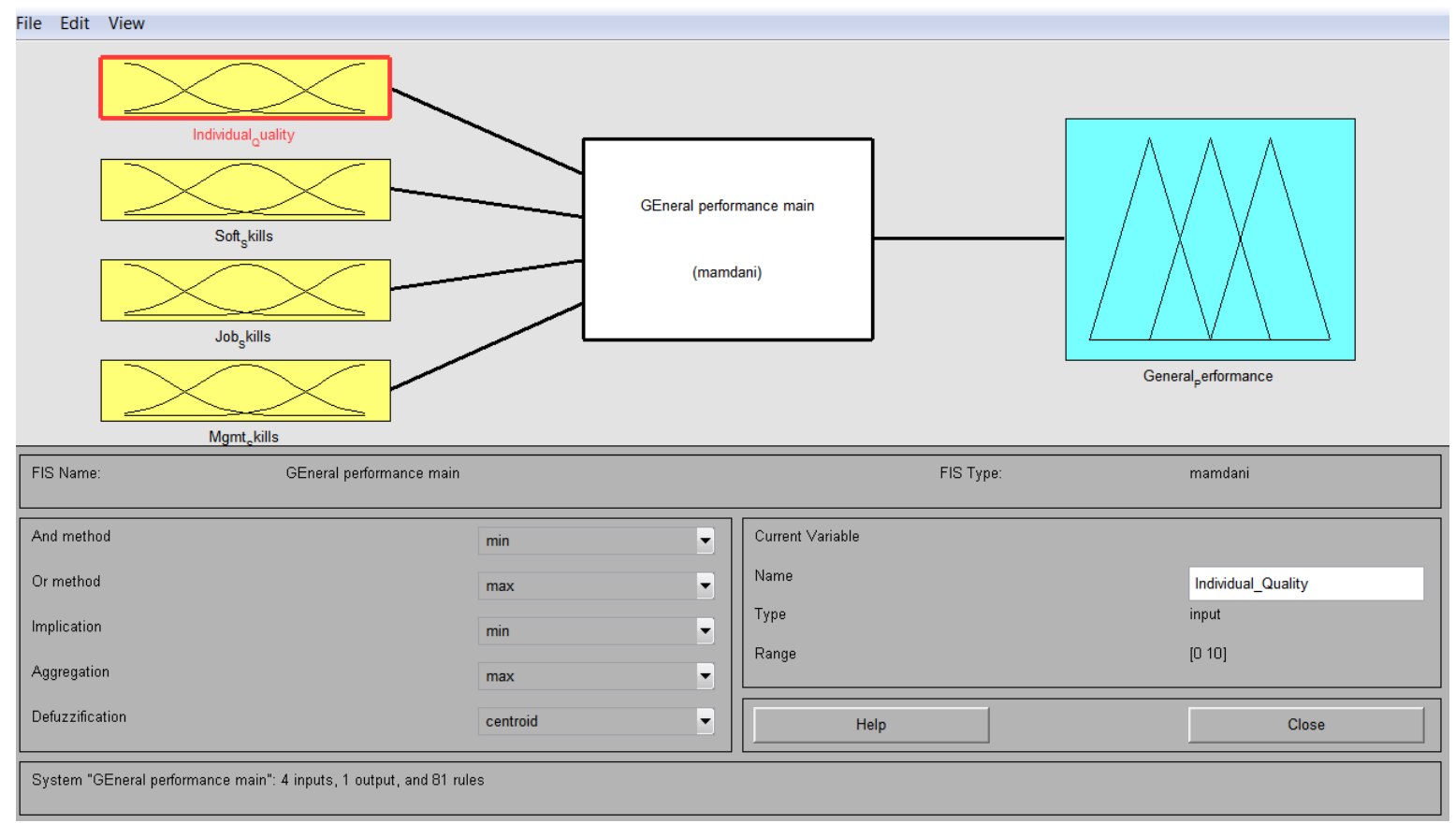

Fig. 4. 'General Performance’ input variable in Fuzzy Expert System

Fig. 5 shows Fuzzification step for final Performance Appraisal based on three main factors as General Performance, Supervisory and Team Based as inputs and
Final Performance Appraisal as final output of the inference system. 
Design and Implementation of Fuzzy Rule

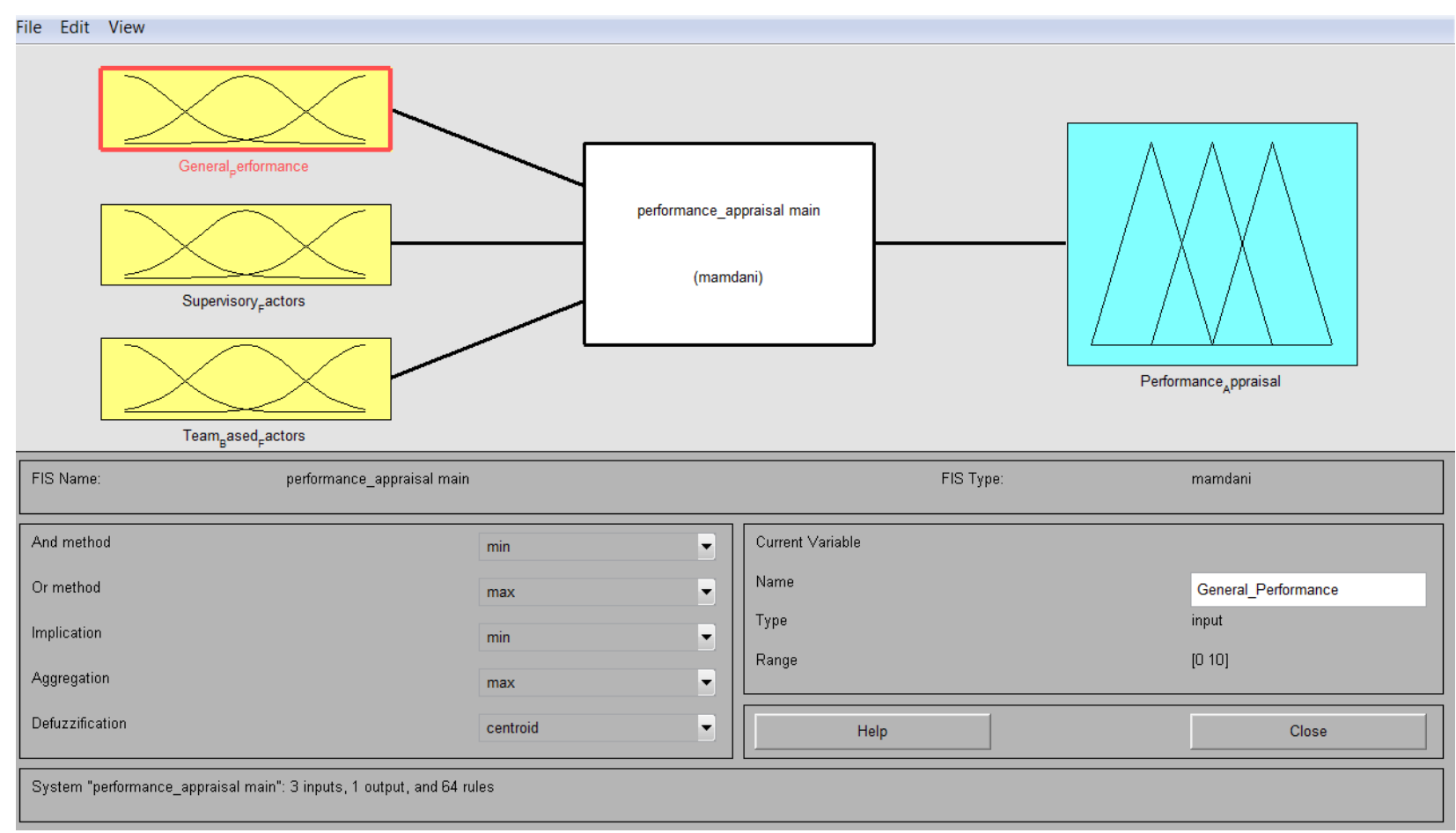

Fig. 5. Fuzzification of inputs for final Performance Appraisal

\section{Fuzzy Rule Construction}

In fuzzy Inference System, based on the knowledge provided by the domain experts, decisions are made and outputs are generated. Collection of this type of knowledge generates a fuzzy knowledge base which is a collection of some fuzzy IF-THEN rules. In this proposed system, 253 such type of fuzzy IF-THEN rules is generated by experts.

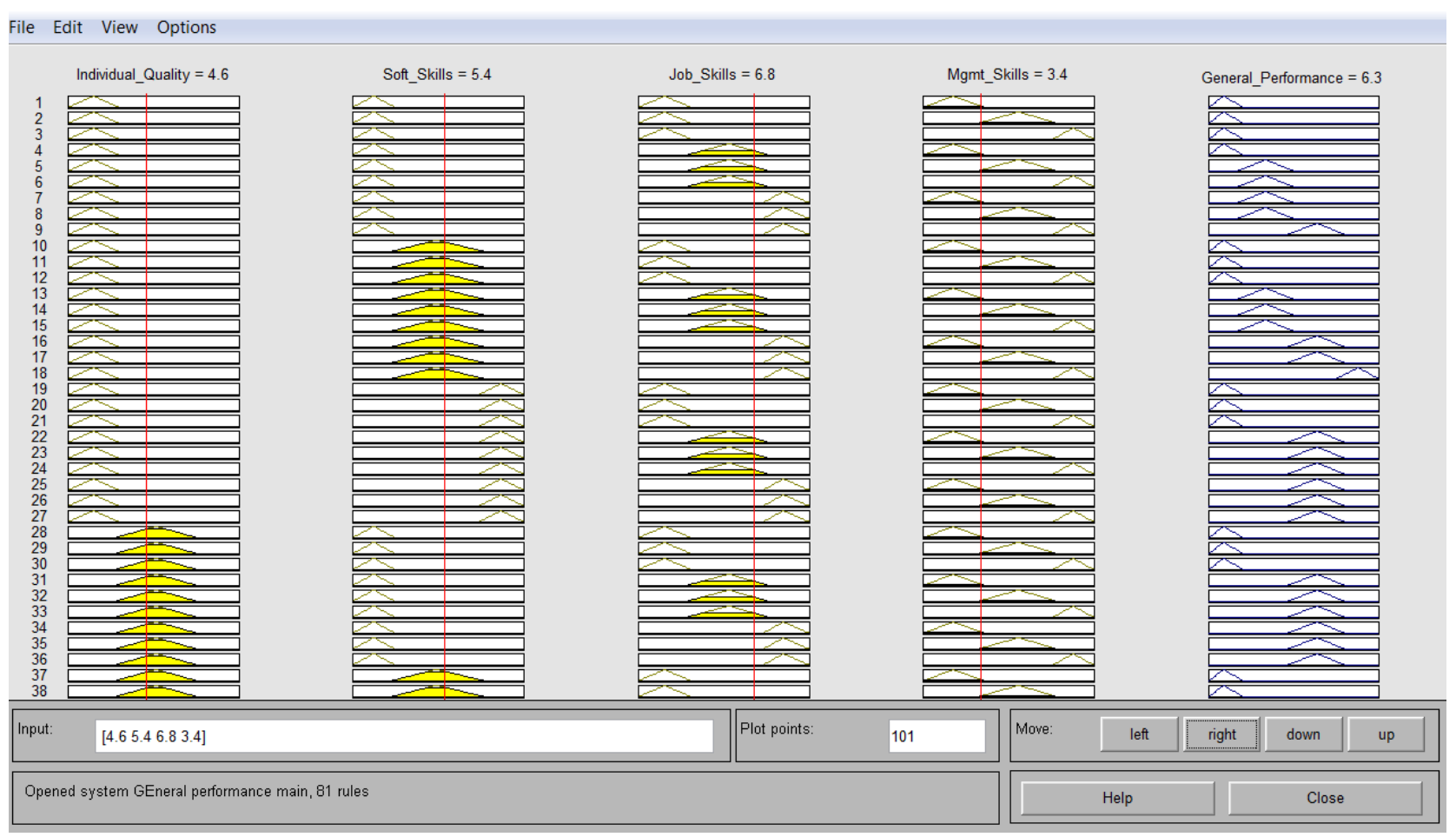

Fig. 6. Fuzzy Rule Base view for evaluating 'General Performance’ Factor.

Fig. 6 shows rules for 'General Performance' based on Individual Quality, Soft Skills, Job related Skills and Management Skills input parameters in MATLAB rule viewer. Fig. 7 shows a sensitive surface view of the same rule base. 


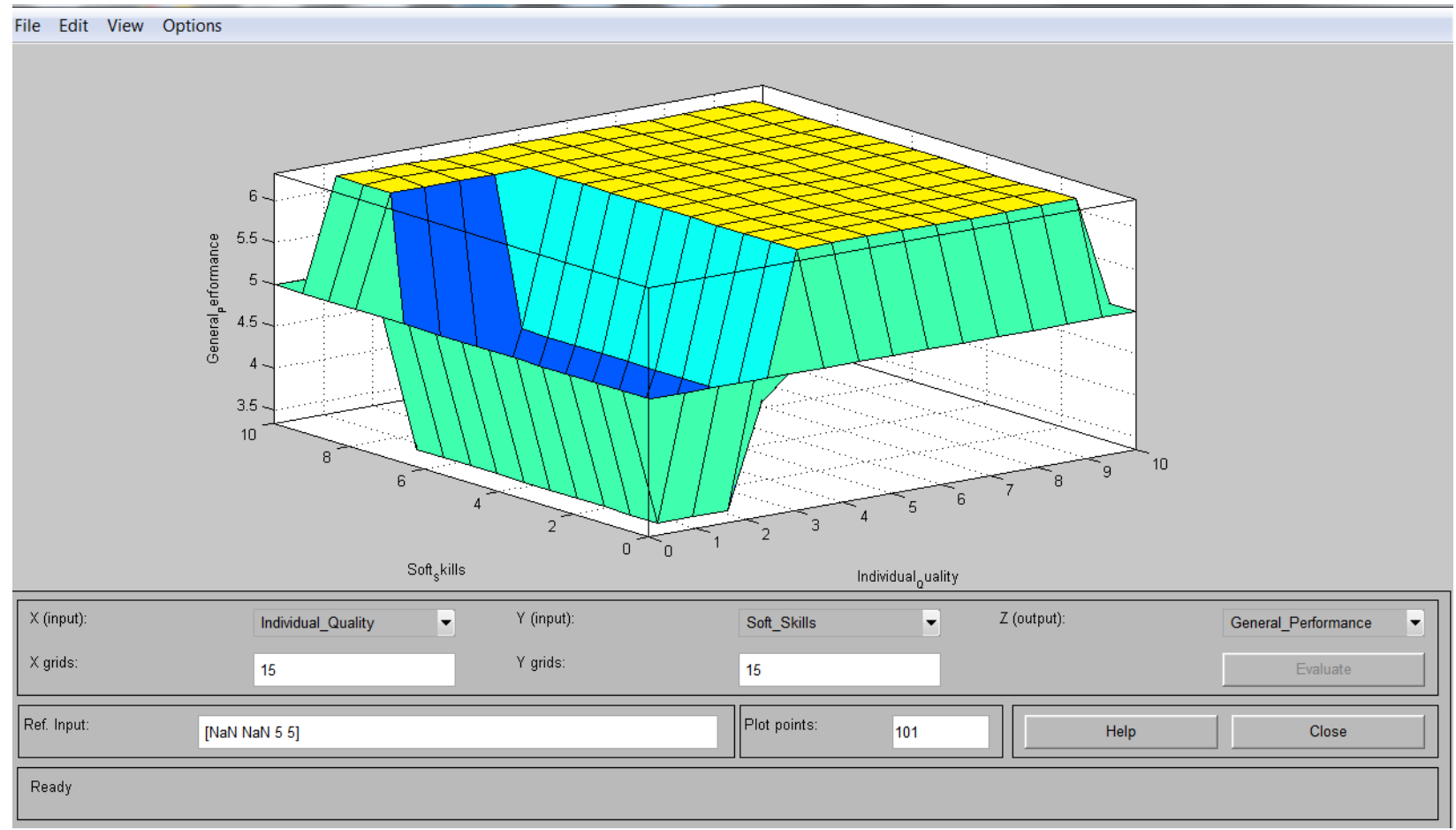

Fig. 7. Surface view of the rule base for evaluating 'General Performance' factor

Some sample IF-THEN rules for 'General Performance' from the rule base are given below:

i) If Individual Quality is Poor AND Soft Skill is Poor AND Job Related Skill is Poor and Management Skill is Poor THEN General Performance is Poor.

ii) If Individual Quality is Good AND Soft Skill is Poor AND Job Related Skill is Good and Management Skill is Excellent THEN General Performance is Good. iii) If Individual Quality is Good AND Soft Skill is Excellent AND Job Related Skill is Excellent and Management Skill is Good THEN General Performance is Excellent.

iv) If Individual Quality is Excellent AND Soft Skill is Excellent AND Job Related Skill is Poor and Management Skill is Poor THEN General Performance is Poor.

Etc.

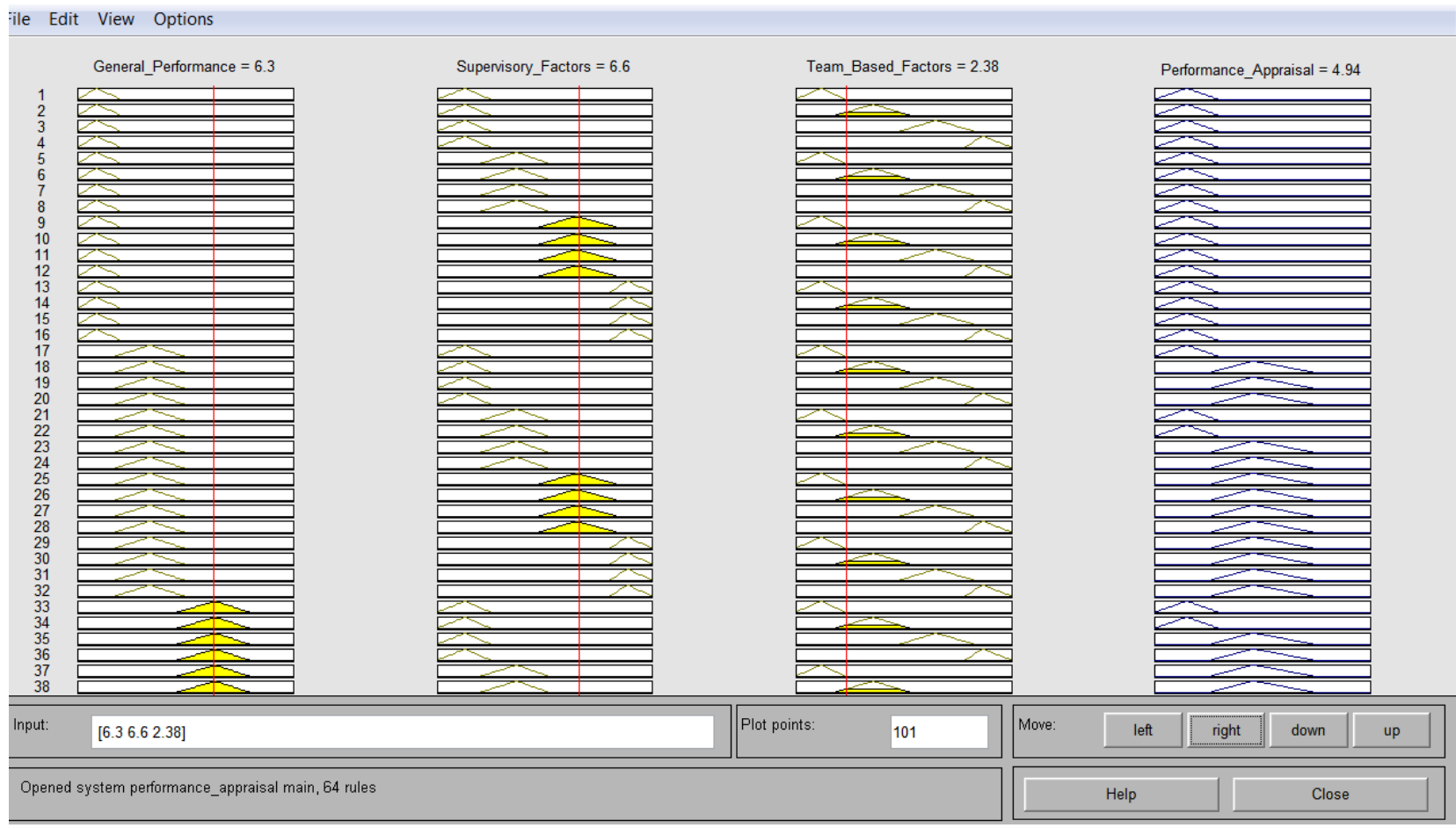

Fig. 8. Fuzzy rule base viewer for final Performance Appraisal 
In this fashion, rule bases are prepared for other factors mentioned in figure according to the specification mentioned in table. Based on the fuzzy outcomes of these intermediate evaluations, final inference system is designed.
Fig. 8 shows the rule base for final appraisal system with three broad factors: General Performance, Supervisory and Team Based as inputs and Final Performance Appraisal as final output of the inference system. Fig. 9 shows a sensitive surface view of the same rule base.

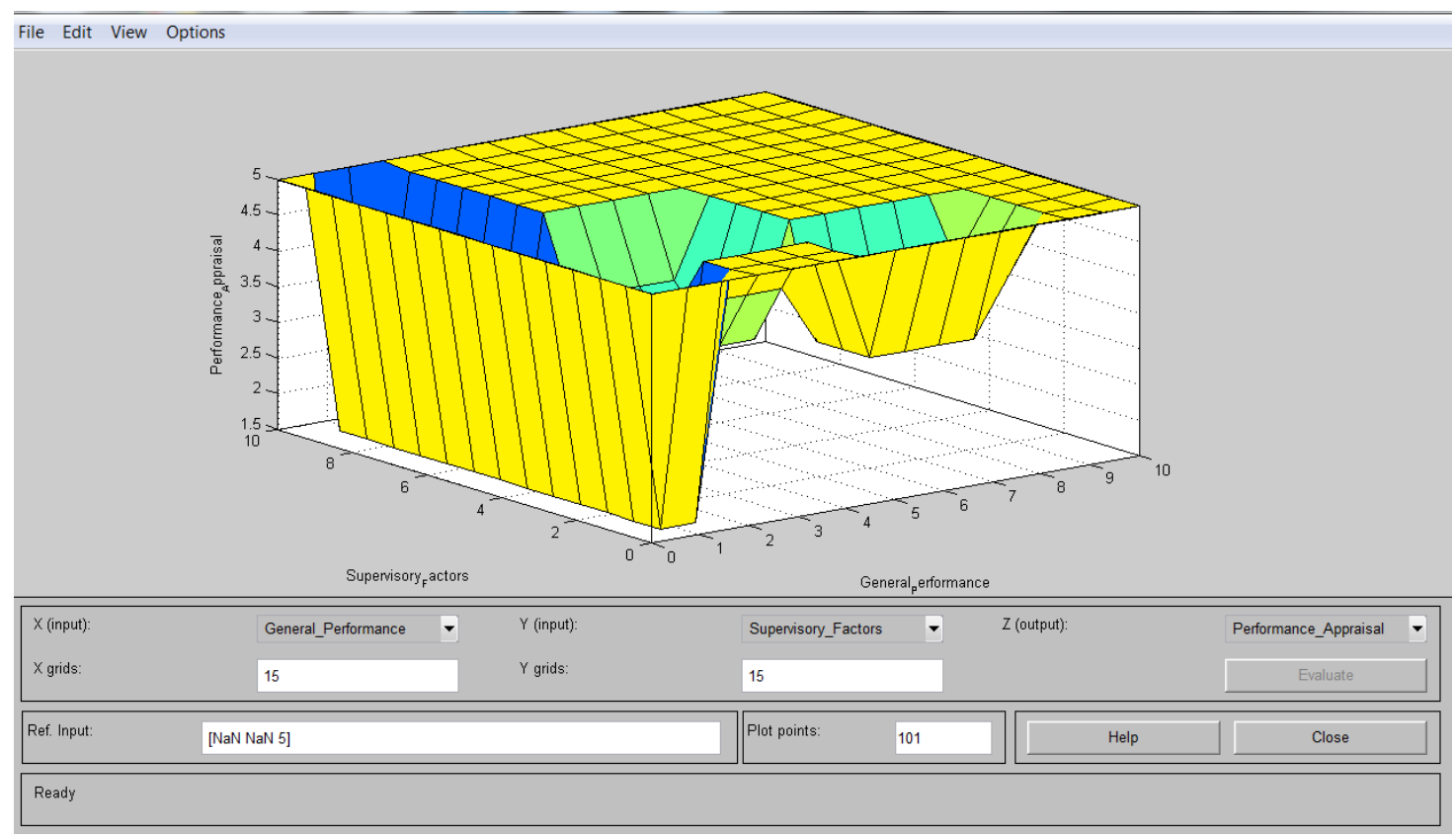

Fig. 9. Surface view of the rule base for Final Performance Appraisal

Table 4. Rankings of different employees after Defuzzification

\begin{tabular}{|c|c|c|c|c|c|c|c|c|c|c|c|c|c|}
\hline \multirow{2}{*}{$\begin{array}{l}\dot{0} \\
\stackrel{0}{0} \\
\stackrel{0}{0} \\
\stackrel{0}{0}\end{array}$} & \multirow{2}{*}{ 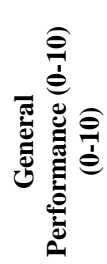 } & \multirow{2}{*}{ 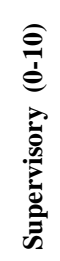 } & \multirow{2}{*}{ 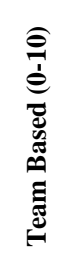 } & \multicolumn{10}{|c|}{$\begin{array}{c}\text { Defuzzified Performances } \\
\text { and Rankings }\end{array}$} \\
\hline & & & & 总 & 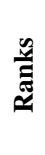 & 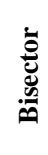 & $\begin{array}{l}\text { चै } \\
\tilde{I}\end{array}$ & 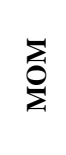 & 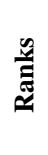 & فำ & 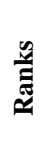 & ¿্ & 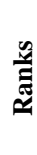 \\
\hline E1 & 6.3 & 6.6 & 2.38 & 4.94 & 3 & 4.9 & 3 & 4.85 & 3 & 6.5 & 3 & 3.2 & 8 \\
\hline E2 & 8.75 & 8.98 & 8.87 & 8.44 & 1 & 8.4 & 1 & 8.35 & 1 & 8.5 & 1 & 8.2 & 1 \\
\hline E3 & 3.35 & 1.25 & 4.31 & 4.9 & 6 & 4.9 & 3 & 4.8 & 4 & 5.8 & 5 & 3.8 & 5 \\
\hline E4 & 7.74 & 6.59 & 4.31 & 4.96 & 2 & 5 & 2 & 4.9 & 2 & 6.9 & 2 & 2.9 & 9 \\
\hline E5 & 6.31 & 1.26 & 3.35 & 1.5 & 10 & 1.5 & 5 & 1.5 & 7 & 1.7 & 9 & 1.3 & 10 \\
\hline E6 & 2.88 & 6.58 & 6.55 & 4.88 & 8 & 4.9 & 3 & 4.75 & 5 & 5.4 & 7 & 4.1 & 3 \\
\hline E7 & 3.35 & 8.98 & 6.54 & 4.87 & 9 & 4.8 & 4 & 4.65 & 6 & 4.8 & 8 & 4.5 & 2 \\
\hline E8 & 2.46 & 6.57 & 8.85 & 4.92 & 4 & 4.9 & 3 & 4.8 & 4 & 6.1 & 4 & 3.5 & 7 \\
\hline E9 & 6.3 & 6.6 & 7.44 & 4.91 & 5 & 4.9 & 3 & 4.85 & 3 & 6.1 & 4 & 3.6 & 6 \\
\hline E10 & 6.32 & 7.22 & 8.87 & 4.89 & 7 & 4.9 & 3 & 4.75 & 5 & 5.6 & 6 & 3.9 & 4 \\
\hline
\end{tabular}

\section{Fuzzy Inference Module Generation}

This module deals with the fuzzy inference engine, which is guided by fuzzy rules. The standard Max-Min (Mamdani) inference algorithm has been used in this fuzzy inference process, as it is considered to be most popular used fuzzy inference strategy.

\section{E. Defuzzification}

The process of obtaining a single number that represent the best outcome of the fuzzy set evaluation is called Defuzzification. There are various methods available for this purpose like Centroid, Bisector, Mean of Maximum (MOM), Smallest of Maximum (SOM), 
Largest of Maximum (LOM) etc. In this study, all these Defuzzification methods are applied using MATLAB to rank the employees mentioned in Table according to their performance appraisal.

\section{F. Evaluating and Ranking the Employees based on their performance}

Finally, using different Defuzzification techniques, employees mentioned in Table 3.2 are ranked based on the defuzzified value of their performance appraisal. The rankings are displayed in Table 3.4.

From Table 4, we can find those employees who were considered for performance appraisal using this proposed model are ranked based on their performance records mentioned in Table 2 using different Defuzzification methods. For example, according to the Table 2, employee E2 had the best scores in the form of General Performance, Supervisory, and Team Based and as expected, according to the Table 4 he ranked top among 10 faculty members in all Defuzzification techniques. In the same way Employee, E5 ranked last in all Defuzzification techniques, which obviously proves the robustness of this model.

\section{CONCLUSION}

This paper proposed a novice method for evaluating performances of employees in IT organization. The method can easily be extended to evaluate performances of employees of any industry, based on some critical factors, which directly or indirectly influence their performances. As it is always advised to elicit knowledge from any domain expert to construct the rule bases in developing any expert system, different higher authorities and HR personnel had been consulted to form those fuzzy rules for our fuzzy knowledge base. Later, after construction of those fuzzy rules, different personnel from administrative, HR and other higher authorities verified those. Finally, the results were shown to them again and the response was very satisfactory. This work can be extended further by introducing uncertainty principle to deal with those rules.

\section{REFERENCE}

[1] S.K. Krishnan, M. Singh (2010). Outcomes of intention to quit of Indian IT Professionals, Wiley, 49(3): 421-437.

[2] M. Armstrong (2006). Performance Management: Key Strategies and Practical Guidelines, Kogan Page Limited, London, UK.

[3] B. Cash (1993). Human Resource Management Handbook, Harvard Business Review, Vol. 3.

[4] K.P. Gallagher, K. M. Kaiser, J.C. Simon (2010). The requisite variety of skills for IT Professionals, Communications of the ACM, 53(6).

[5] C. Moon, J. Lee, C. Jeong, J. Lin, S. Park, S. Lim (2007). An implementation case for the performance appraisal and promotion ranking, IEEE International Conference on Systems, Man and Cybernetics, 2007, ISIC, Page: 661-667.

[6] X. J. Chen, J. P. Zhu, X.Y. Xie, Z.H. Lin (2006). Modeling the performance in Chinese Engineering Managers, IEEE
International Engineering Management Conference, Page: 75-77.

[7] P. Jackson (1990). Introduction to expert systems. England: Addison-Wesley.

[8] K. Darlington (2000), The essence of expert system, England: Prentice-Hall.

[9] L. A. Zadeh (1965). Fuzzy sets, Information and Control, Vol 8: 338-353.

[10] A. Abraham (2005). Rule - Based Expert Systems. Handbook of measuring system design. Wiley.

[11] A. Hajiha, J. J. Jassbi, S. Khanmohammadi (2007). A Fuzzy Expert Decision Support System for Job Assignment, IEEE International Fuzzy Systems Conference, FUZZ-IEEE 2007. Page: 1-4.

[12] W. H. Lai, C.T. Tsai (2008). Analyzing Influence Factors of Technology Transfer Using Fuzzy Set Theory, PICMET, Page: 2287-2295.

[13] J. Rezaei, S. Dowlatshahi (2010). A rule based multicriteria approach to inventory classification, International Journal of Production Research, 48(23): 7107-7126.

[14] M. Fasanghari, G. A. Montazer, (2010). Design and implementation of fuzzy expert system for Tehran Stock Exchange portfolio recommendation. Expert Systems with Applications, 37(9), 6138-6147.

[15] T. J. Ross (2005). Fuzzy logic with engineering applications. John Wiley \& Sons.

[16] Anupama, T. D. Binu M., T. Dulababu (2011). The Need of '720 Degree Performance Appraisal' in the New Economy Companies, International Research of Multidisciplinary Research, 1(4).

[17] A. Neogi, A. C. Mondal, S. K. Mandal (2011). A Cascaded Fuzzy Inference System for University Non-Teaching Staff Performance Appraisal, Journal of Information Processing Systems, 7(4).

[18] O. K. Chaudary, P.G. Khot, K. C. Deshmukh (2012). Soft Computing Model for Academic Performance of Teachers Using Fuzzy Logic, British Journal of Applied Science \& Technology, 2(2):213-226.

[19] N. Sapra (2012).Current trends in Performance Appraisal, IJRIM,2(2).

[20] S. Pavani, P.V. S. S. Gangadhar, K. K. Gulhare (2012). Evaluation of Teacher's Performance using Fuzzy Logic Techniques, International Journal of Computer Trends and Technology, 3(2).

\section{Authors' Profiles}

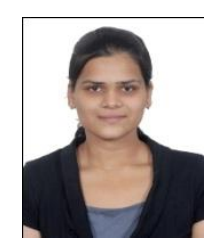

Ashima Aggarwal, M.tech from Lovely Professional University, Punjab, India, B.Tech (CSE). Area of Interests are Fuzzy logic, Data structures, Real Time Systems and Neural Networks.

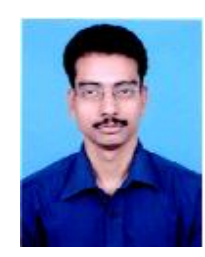

Gour Sundar Mitra Thakur, Asst. Professor (CSE/IT), Dr. B. C. Roy Engineering College, Durgapur, West Bengal, India. B.Tech (C.S.E.), M.tech (CS).Currently pursuing $\mathrm{PhD}$ from National Institute of Technology, Durgapur in Mathematics, Areas of Interests are Fuzzy Logic and Fuzzy Mathematics, Soft Computing, Intelligent Systems and Neural Networks. 